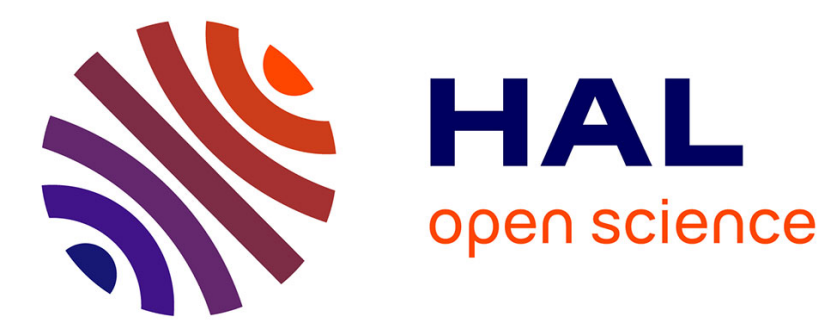

\title{
Interference microscopy on thin diblock copolymer films
}

G. Coulon, D. Ausserre, T.P. Russell

\section{To cite this version:}

G. Coulon, D. Ausserre, T.P. Russell. Interference microscopy on thin diblock copolymer films. Journal de Physique, 1990, 51 (8), pp.777-786. 10.1051/jphys:01990005108077700 . jpa-00212408

\section{HAL Id: jpa-00212408 https://hal.science/jpa-00212408}

Submitted on 1 Jan 1990

HAL is a multi-disciplinary open access archive for the deposit and dissemination of scientific research documents, whether they are published or not. The documents may come from teaching and research institutions in France or abroad, or from public or private research centers.
L'archive ouverte pluridisciplinaire HAL, est destinée au dépôt et à la diffusion de documents scientifiques de niveau recherche, publiés ou non, émanant des établissements d'enseignement et de recherche français ou étrangers, des laboratoires publics ou privés. 
Classification

Physics Abstracts

$68.00-64.70-78.65$

\title{
Interference microscopy on thin diblock copolymer films
}

\author{
G. Coulon (1), D. Ausserre ( $\left.{ }^{1}\right)$ and T. P. Russell ( $\left.{ }^{2}\right)$
}

( $\left.{ }^{1}\right)$ Institut Curie, Section de Physique et Chimie (*), 11 rue Pierre et Marie Curie, 75231 Paris Cedex 05, France

(2) IBM Research Division, Almaden Research Center, 650 Harry Road, San Jose, California 95120-6099, U.S.A.

(Reçu le 20 octobre 1989, accepté le 22 décembre 1989)

Résumé. - A l'équilibre thermodynamique, les films minces de copolymères diblocs, symétriques, se présentent sous la forme d'un empilement lamellaire orienté parallèlement aux surfaces externes. L'observation des couleưrs d'interférence par microscopie optique a été utilisée ici pour étudier ce processus d'orientation et la quantification de l'épaisseur du film qui en résulte. L'observation de films non recuits de copolymères diblocs, symétriques polystyrène/polyméthylméthacrylate $\mathrm{P}(\mathrm{S}-\mathrm{b}-\mathrm{MMA})$ révèle la présence d'une seule couleur d'interférence (bleu), ce qui indique que l'épaisseur du film est uniforme et que sa surface libre est plane. Si on recuit ces films à $170^{\circ} \mathrm{C}$ pendant 24 heures et plus, on constate l'existence de deux couleurs d'interférence (bleu indigo et marron clair). Les variations de couleur sont discrètes et non pas continues; elles correspondent à des marches d'épaisseur de hauteur égale à la période de l'empilement lamellaire. La surface libre du film se présente comme un fond uniforme bleu indigo constellé de taches marron clair réparties uniformément ; ces taches correspondent à des trous. La taille moyenne et la distribution spatiale de ces trous varient avec le temps de recuit. Le comportement observé semble présenter des analogies avec une transition de phase à deux dimensions.

Abstract. - At equilibrium thin films of symmetric diblock copolymers exhibit a morphology where the lamellar microdomains are oriented parallel to the external surfaces. Interference microscopy has been used to investigate this orientation which results in a quantization of the film thickness. Solution cast films of the symmetric polystyrene/polymethylmethacrylate P(S-b-MMA) diblock copolymers exhibit a single interference color characteristic of a film of uniform thickness with a free surface that is flat and smooth. Interference microscopy on these films annealed at $170{ }^{\circ} \mathrm{C}$ for 24 hours and more shows the development of two distinct interference colors. The variations in the colors are discrete rather than continuous indicating step discontinuities in the film thickness with a height equal to one period of the underlying oriented lamellar multilayer. The free surface topology is such there are patches of one color spread across the surface on a uniform background, i.e., there are islands or depressions on the surface. The average size and spatial distribution of these islands or depressions are found to vary with annealing time ; the appearance of the free surface is reminiscent of a two-dimensional phase coarsening process. The time dependent change in the case of depressions is reported herein.

(*) CNRS (URA 1379) et Université Paris 6. 


\section{Introduction.}

At equilibrium, symmetric diblock copolymers, the case of interest here, exhibit a lamellar microdomain morphology. Theory predicts [1-4] that the equilibrium spatial period, $L$, varies with the degree of polymerization $N$ as $L \propto N^{p}$ where $p$ is $1 / 2$ in the weak segregation case and $2 / 3$ in the strong segregation limit. In the present study, we have investigated poly(styrene)/poly(methylmethacrylate), P(S-b-MMA) symmetric, diblock copolymers which have been shown to be in the weak segregation limit for total molecular weights less than 35,000 and in the strong segregation limit at higher molecular weights [5, 6]. The experimental lamellar period of $\mathrm{P}(\mathrm{S}-\mathrm{b}-\mathrm{d}-\mathrm{MMA})$ (where PMMA is perdeuterated) was found to vary from c.a. $175 \AA$ to c.a. $520 \AA[7,8]$ when the total molecular weight of the copolymer increased from 29,780 to 121,300 .

Microphase separation results in properties not seen in homopolymers. In fact, the macroscopic properties (mechanical, optical and structural) can be tailored during synthesis by control of the block molecular weight. Consequently, block copolymers in bulk have been studied for many years due to their technological importance $[9,10]$. Block copolymers also exhibit interesting surface activity. The difference in the surface energies of the two components causes preferential adsorption of one component to the surface. It is precisely this behavior that leads to the application of copolymers as membranes and adhesion promoters. Up to now, few studies have dealt with surface induced ordering of block copolymers. X-ray photoelectron spectroscopy $[11,12]$, transmission electron microscopy [13, $14]$ and neutron reflectivity studies $[6,8]$ have shown that, at equilibrium, the lower surface energy component is preferentially located at the free surface. For microphase separated diblock copolymers this preferential surface activity gives rise to a stacking of the lamellae parallel to the surface [6-8, 13-15] which can propagate large distances into the specimen.

In this study interference microscopy has been used to investigate the free surface topology of thin films of symmetric P(S-b-MMA) copolymers. A photomicroscope was used under reflection conditions to obtain interference colors from the white source. The colors, produced by the interference of the light waves reflected from the upper and lower surfaces of the film, correspond to specific thicknesses. By use of this technique the variation in the specimen thickness over lateral length scales greater than $1 \mu \mathrm{m}$ can be quantitatively assessed. For the copolymers of interest, the lamellar multilayers orient parallel to the film surface and have been shown to develop terraces with step heights corresponding to one period of the lamellar microdomain morphology. In this report it is shown that the free surface of solution cast film is flat and smooth, but that upon annealing at temperatures above the glass transition temperature of the two blocks, elevations or depressions are formed and distributed uniformly over the entire surface of the film. The average size and spatial distributions of the islands or depressions change with the annealing time. Thus, these systems may represent a model system by which two-dimensional coarsening behavior can be investigated.

\section{Experimental.}

Four symmetric, diblock P(S-b-MMA) copolymers, purchased from Polymer Laboratories, were used in this study. Their characteristics are given in table I. The molecular weights of the blocks, $M_{\mathrm{PS}}$ and $M_{\mathrm{PMMA}}$, were determined by size exclusion chromatography referenced to polystyrene standards. Copolymer films, c.a. $900 \AA$ in thickness, were prepared by spin coating toluene solutions of the copolymers onto a silicon substrate (diameter $2.5 \mathrm{~cm}$ ). It should be noted that toluene is a good solvent for both PS and PMMA. The copolymer films on the substrates were investigated in the as-cast and annealed states. The annealed samples were obtained by heating the specimens to $170{ }^{\circ} \mathrm{C}$ under vacuum over a four hour period. 
Table I. - Characteristics of Symmetric Diblock P(S-b-MMA) Copolymers.

\begin{tabular}{lcc}
\hline \multicolumn{1}{c}{ Copolymer } & $M_{\mathrm{PS}} / M_{\mathrm{PMMA}}{ }^{*}$ & Polydispersivity ${ }^{\dagger}\left(M_{\mathrm{W}} / M_{\mathrm{n}}\right)$ \\
\hline P(S-b-MMA) & $58,600 / 55,000$ & 1.10 \\
P(S-b-d-MMA) & $56,300 / 65,000$ & 1.12 \\
P(d-S-b-MMA) & $52,900 / 48,000$ & 1.07 \\
P(d-S-b-d-MMA) & $55,900 / 59,200$ & 1.10 \\
\hline
\end{tabular}

* $M_{\mathrm{PS}}$ and $M_{\mathrm{PMMA}}$ correspond to the values of the molecular weight determined via gel permeation chromatography.

$\dagger M_{\mathrm{W}}$ and $M_{\mathrm{n}}$ are the weight and number average molecular weights of the total copolymer.

After specimens were annealed at $170{ }^{\circ} \mathrm{C}$ for the desired period, they were slowly cooled to room temperature under vacuum. In the following, " annealing time » refers to the duration of the entire heating and cooling procedure. In this report, annealing times of 24 and 72 hours were used.

A Zeiss Axiophot Pol photomicroscope was used under reflection conditions to obtain interference colors from the white light source. The source lamp iris was closed down to ensure a parallel beam of light. All the color figures shown have been reproduced from color slides (Kodak Ektachrome film, 160 ASA, for a tungsten lamp).

\section{Results and discussion.}

Prior to annealing, the specimens are in a state far from equilibrium. Previous studies [7] have shown that the equilibrium morphology within the specimen was reached within 24 hours of annealing. This is characterized by a lamellar structure parallel to the surface of the copolymer film such that a PMMA layer was found adjacent to the silicon wafer and a PS layer on the free surface [5-8]. These two observations mandate that the total thickness of the film at any point corresponds to $(i+1 / 2) L$ where $i$ is the number of periods of length $L$ given by the center-to-center distance of successive PMMA layers in the bulk. The initial thickness of the film is determined by the amount of copolymer deposited onto the substrate. It is very unlikely that this thickness corresponds exactly to $(i+1 / 2) L$ where $i$ is an integer. Thus, the equilibrium periodic structure cannot be reached while maintaining the initial thickness. Several scenarios can be envisaged. First, the thickness of the film could be held fixed thereby varying $L$. By changing the thickness of the lamellae, it may be possible to modify the interface to volume ratio of the morphology within the sample. This implies extension or contraction of the polymer chains in the microdomains. Secondly, an incomplete layer of the copolymer material at the free surface of the sample could be formed. This could be achieved either by dispersing the excess copolymer uniformly on the surface or by the formation of elevations or terraces on the surface.

Figure 1a shows an optical micrograph of an as-cast P(d-S-b-MMA) (860 ̊ thick). Apart from the perimeter of the sample, the entire surface exhibits an uniform, blue indigo color. After annealing at $170{ }^{\circ} \mathrm{C}$ for 24 hours, as well as for 72 hours, the surface exhibits a structured morphology comprised of light brown patches distributed over the indigo blue background as shown in figure $1 \mathrm{~b}$ and figure $1 \mathrm{c}$. Figure $1 \mathrm{~b}$ shows clearly that after annealing at $170{ }^{\circ} \mathrm{C}$ for 24 hours there is a large number of very small patches all over the surface. Increasing the annealing time up to 72 hours leads (Fig. 1c) to a drastic decrease of the 


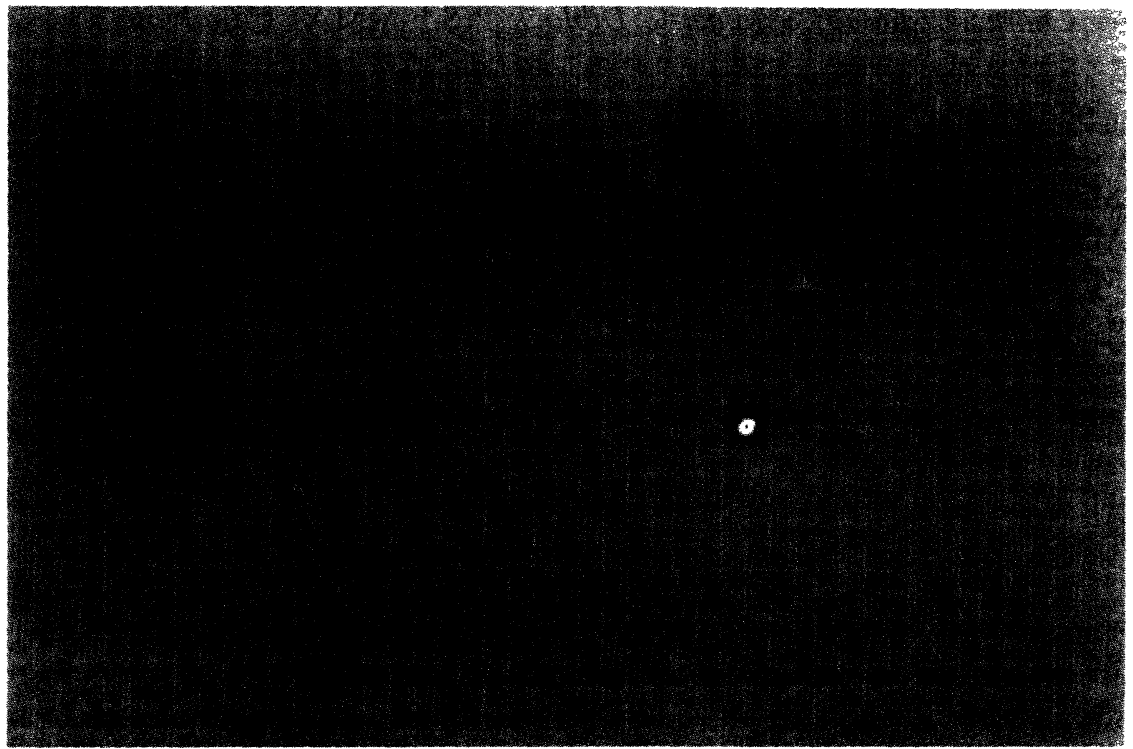

(a)

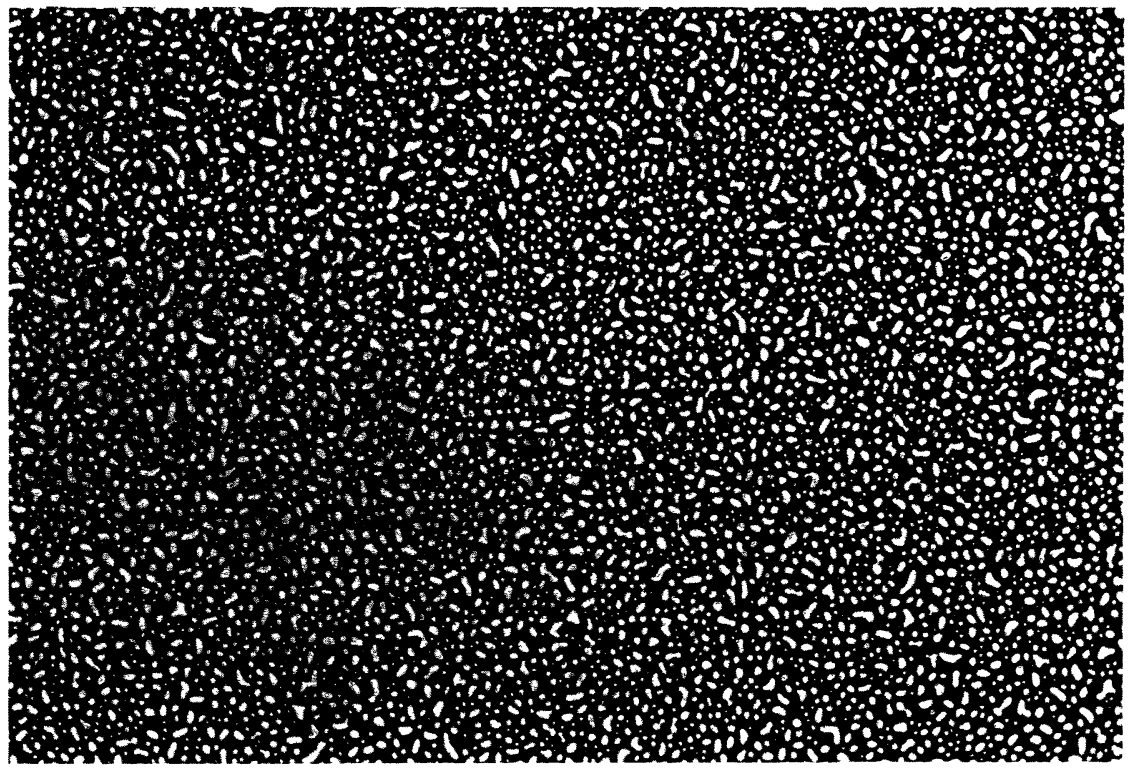

Fig. 1. - Optical micrographs of the central part of a P(d-S-b-MMA) copolymer sample spin coated onto a silicon wafer from a toluene solution : (a) interference colors observed in the case of the as-cast sample : the central part is characterized by an indigo blue uniform background ; (b) interference colors observed in the case of a sample annealed at $170{ }^{\circ} \mathrm{C}$ for 24 hours : light brown patches are spread over the indigo blue background ; (c) interference colors observed in the case of a sample annealed at $170{ }^{\circ} \mathrm{C}$ for 72 hours and (d) Nomarski interferential contrast obtained in the case of an annealed sample. This micrograph was obtained, when working in the polarizing mode, with the polarizer and the analyzer slightly shifted from their crossed position to increase the light intensity on the film so as to operate with reasonable exposure times. Nevertheless, it is obvious that the patches are demarcated from the background by white contours proving the existence of sharp steps. The full, long dimension of the a, b, c micrographs is $280 \mu \mathrm{m}$ whereas that for micrograph $\mathrm{d}$ is $140 \mu \mathrm{m}$. 

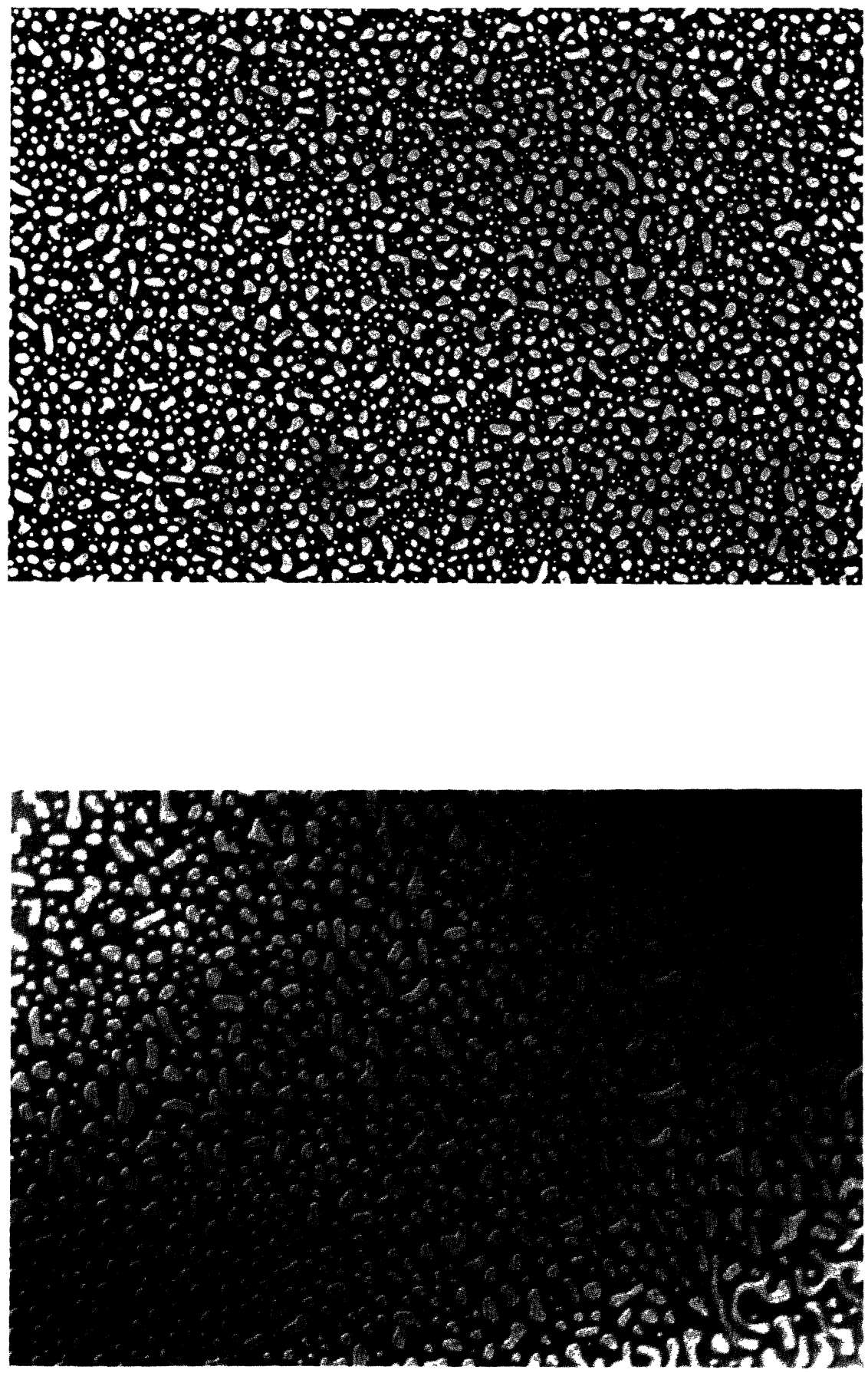

(d) 
population of these small patches and to an increase of the number of larger ones. Digital image processing has been used to identify the distribution of the diameters of the patches. After 24 hours, the distribution exhibits a broad maximum for a mean diameter of $1 \mu \mathrm{m}$, whereas after 72 hours the maximum is located at $1.7 \mu \mathrm{m}$. However, the population density of the $1 \mu \mathrm{m}$ patches still present after 72 hours represents only a fraction (45\%) of the one after 24 hours. At the same time, the population density of the $3.7 \mu \mathrm{m}$ patches has increased by a factor of 3.5 and even larger patches (c.a. $5 \mu \mathrm{m}$ ) not present after 24 hours have now appeared. Close examination of figure 1c indicates that some of the larger patches are produced by the coalescence of smaller ones. In both cases, ( 24 and 72 hours), the shapes of the patches are nearly circular and their boundaries are well defined. Quantitative studies are now in progress dealing with the time evolution of the size and size distributions of these depressions. Observations by Nomarski interferential contrast microscopy [16], shown in figure 1d, demonstrate unequivocally that the contours of these patches correspond to sharp steps on the surface (within the lateral resolution of the microscope, i.e., less than $1 \mu \mathrm{m}$ ). Indeed, Nomarski interferential contrast allows direct detection of the thickness gradient while interference microscopy allows direct visualization of the thickness. In most cases, the thickness gradient detected by Nomarski interferential contrast is localized over distances much smaller than the microscope resolution. The indigo blue and light brown colors shown in figure $1 b$ and figure $1 c$ are among the first colors of the Newton's scale. It is well known it is not possible to evaluate absolute thicknesses by using the Newton's scale. However, in our particular case, as it is explained below, the film thickness varies by constant steps and thus, by using a large number of successive interference colors, we have been able to measure precisely the height of the steps on the free surface.

Due to the spin coating process, the perimeter of the specimen exhibits thickness variations that can be large (up to $6000 \AA$ ). Figure 2 a shows an optical micrograph of the perimeter of one as-cast P(d-S-b-MMA) sample. As can be seen, the interference colors are very diffuse, showing that the thickness varies continuously. After annealing at $170{ }^{\circ} \mathrm{C}$ for 72 hours, welldefined contours of interference colors are evident as shown in figure $2 b$, indicating that the thickness varies in a stepwise manner. Nomarski interferential contrast experiments corroborate the presence of step changes in the thickness. Only the existence of a lamellar stacking parallel to the surfaces can explain the terracing of the free surface. This is in agreement with the above mentioned studies [6-8]. A model of multilayer stacking deduced from these studies is shown in figure 3 and was used to evaluate the step heights.

By using the Newton's scale, the observed successive interference colors can be indexed assuming the steps have the same height, $H$. In the present case, up to 15 colors have been identified (Tab. II). The optical path (o.p.) corresponding to the $(i+1)$ th color in the sequence of the observed interference colors can be written as :

$$
\text { (o.p. ) }=2 \bar{n}(i+1 / 2) H
$$

where the mean refractive index $\bar{n}$ was taken as $1.55\left(n_{\mathrm{PS}}=1.6\right.$ and $\left.n_{\mathrm{PMMA}}=1.5\right)$. The height of the steps has to satisfy equation (1) for each value of $i$. For example, in the case of the light brown color $(i=1)$, the optical path given by the Newton's scale is c.a. $1580 \pm 600 \AA$, and therefore the corresponding height is : $340 \pm 130 \AA,(\Delta H / H \simeq 0.4)$. Equation (1), however, is much more restrictive for colors corresponding to large $i$. As an example, for the 10th color (yellow), the optical path is equal to $11510 \pm 500 \AA$ and the corresponding height is $390 \pm 17 \AA,(\Delta H / H \simeq 0.04)$.

For the P(d-S-b-MMA) copolymer under study, the height $H$ had to satisfy equation (1) simultaneously for all the values of $i$ less than or equal to 15 . To within an accuracy of $2.5 \% \mathrm{H}$ is found to be $390 \AA$. The values given in table III show that, for the four different kinds of 


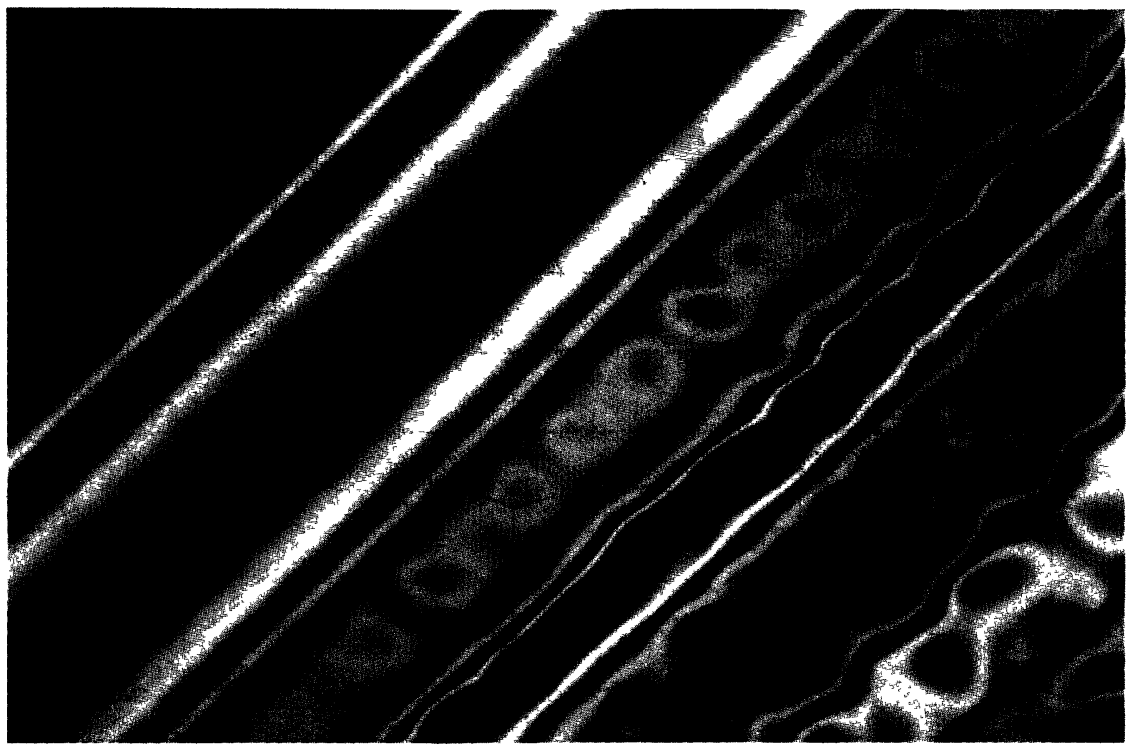

(a)

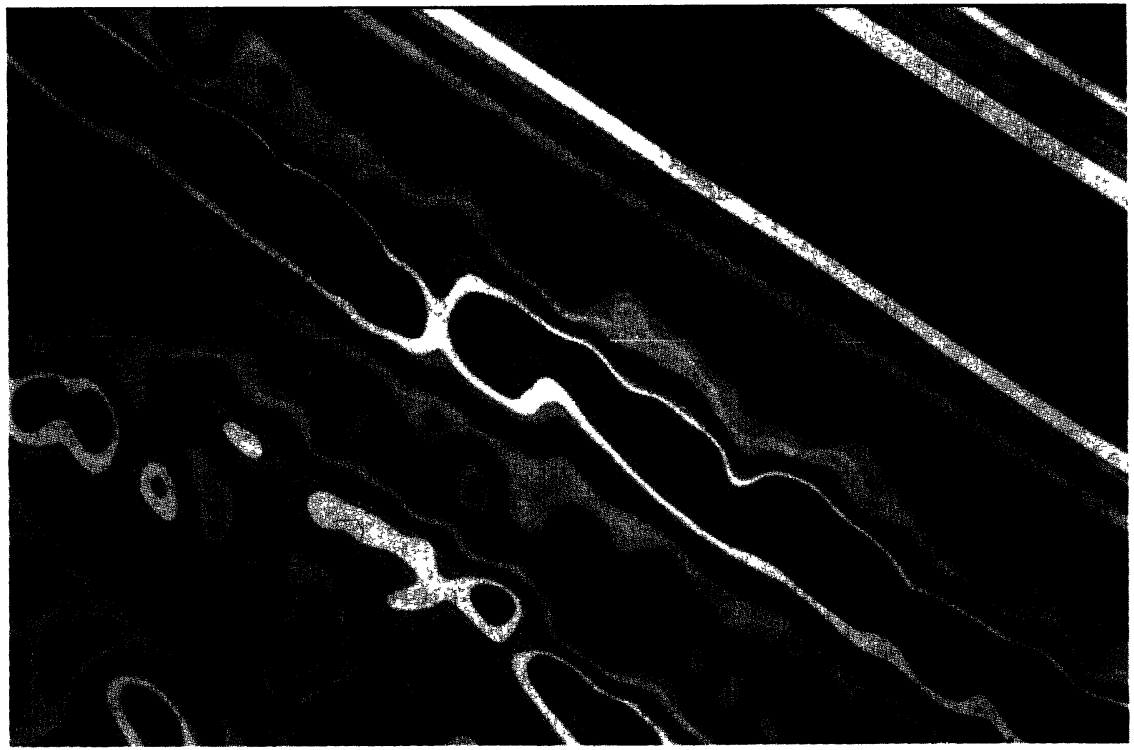

(b)

Fig. 2. - Optical micrographs of the perimeter of a P(d-S-b-MMA) copolymer sample spin coated onto a silicon wafer from a toluene solution : (a) diffuse interference colors observed in the case of the ascast sample and (b) well-defined interference colors obtained in the case of the sample annealed at $170{ }^{\circ} \mathrm{C}$ for 72 hours. The full, long dimension of the micrographs is $280 \mu \mathrm{m}$. 


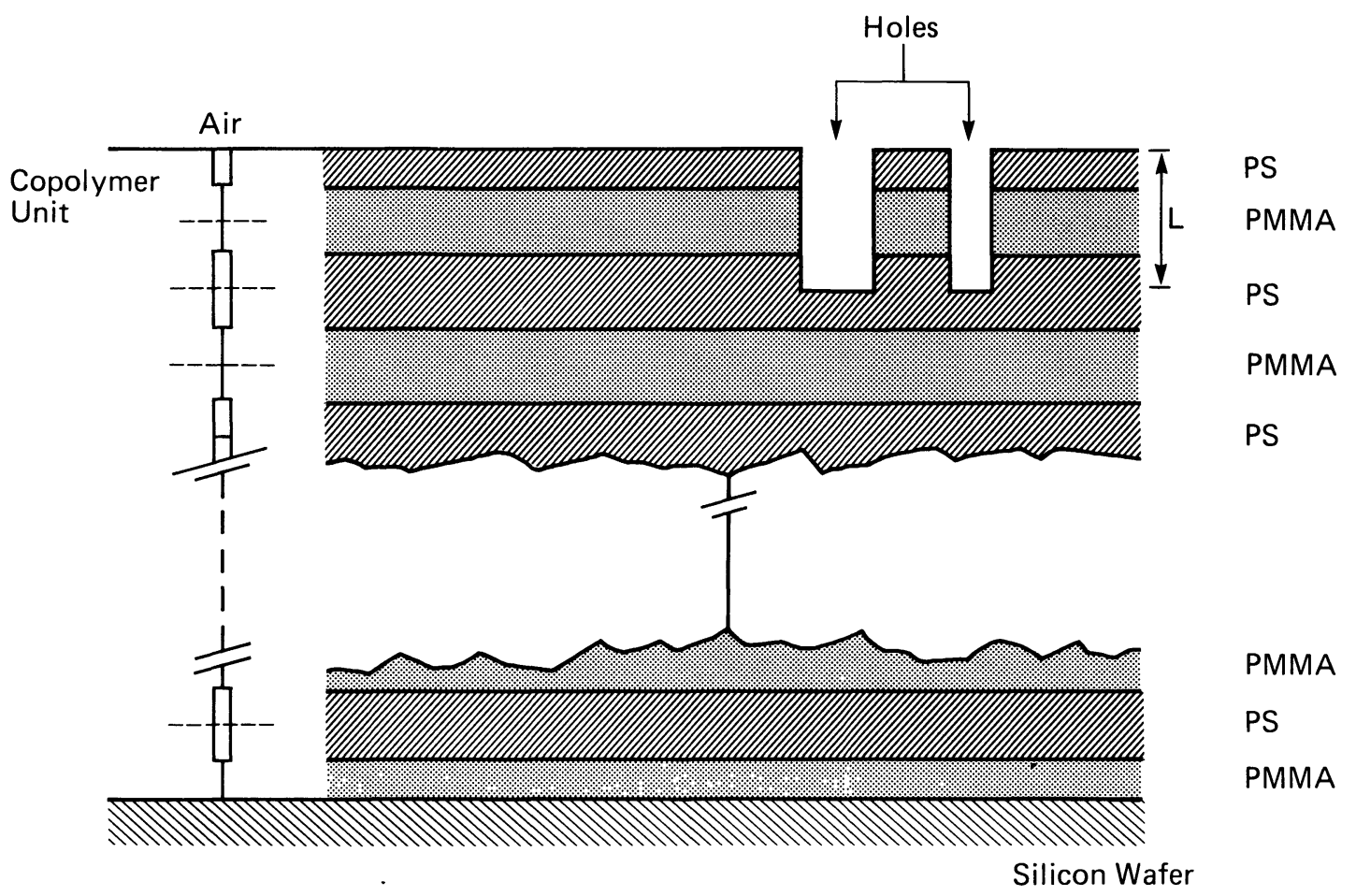

Fig. 3. - Lamellar stacking deduced from SIMS experiments and used for the determination of the height of the steps by interference spectroscopy. Each lamella is a bilayer of one component either PS or PMMA. The thickness of the PS layer at the air/copolymer and the one of the PMMA layer at the copolymer/silicon surface are half the one of the inner lamellae. The period $L$ corresponds to the total thickness of two successive PS and PMMA lamellae. Some holes (patches) are represented in the top layer, in a very schematic way. More especially, concerning the edges of the holes, the polymer adjacent the holes should be PS as it is suggested by the surface segregation at the air/copolymer interface.

block copolymers, the steps observed at the perimeter of the air/copolymer surface, correspond to the period of the lamellar morphology as measured by small angle X-ray scattering on bulk samples [5].

The light brown and indigo blue colors observed in the central part of the air/copolymer surface (Fig. 1b and Fig. 1c) fall in the spectrum of interference colors characteristic of the perimeter of the sample. They correspond, respectively, to the 2 nd and the 3 rd colors (Tab. II). This means that, after annealing at $170{ }^{\circ} \mathrm{C}$ for 24 hours or 72 hours, the air/copolymer surface is no longer flat, but is studded with numerous depressions (light brown patches), the depth of which is equal to one period of the lamellar stacking. Within each region, however, the surface is smooth to within the resolution of the measurement. This morphology can be explained as follows. After annealing above $T_{\mathrm{g}}$, the liquid copolymer rearranges into lamellar microdomains that lie parallel with respect to the surface. This is similar to structures that are observed in smectic liquid crystalline compounds. The sample has to accommodate both the initial imposed thickness and the periodic conditions perpendicular to the surface. The excess copolymer (incomplete, surface layer) forms islands on the underlying multilayered film. This incomplete layer, however, microphase separates in a manner identical to and in register with the existing underlying multilayer. In the example 
Table II. - P(d-S-b-MMA) Copolymer Annealed 72 Hours at $170{ }^{\circ} \mathrm{C}$. Sequence of Observed Interference Colors.

\begin{tabular}{lcc}
\hline \multicolumn{1}{c}{ Color } & Number $(i+1)$ & Optical Path * $(\AA)$ \\
\hline Yellowish white & 1 & 604 \\
Lightbrown & 2 & 1,813 \\
Indigo Blue & 3 & 3,020 \\
Grey Blue & 4 & 4,228 \\
Greenish Yellow & 5 & 5,436 \\
Orange & 6 & 6,644 \\
Scarlet & 7 & 7,852 \\
Indigo & 8 & 9,060 \\
Bluish Green & 9 & 10,268 \\
Yellow & 10 & 11,476 \\
Lightpink & 11 & 12,684 \\
Mauve & 12 & 13,892 \\
Lightgreen & 13 & 15,100 \\
Darkgreen & 14 & 16,308 \\
Pinkish Grey & 15 & 17,516 \\
\hline
\end{tabular}

* The optical path is deduced from the Newton's scale and from equation (1) with $H=390 \AA$ A.

Table III. - Periodicity of diblock copolymers.

\begin{tabular}{lcc}
\hline \multicolumn{1}{c}{ Copolymer } & $\begin{array}{c}\text { Measured Period by } \\
\text { SAXS }\end{array}$ & $\begin{array}{c}\text { Step Height From } \\
\text { Interference Microscopy }\end{array}$ \\
\hline P(S-b-MMA) & $465 \pm 10 \AA$ & $480 \pm 10 \AA$ \\
P(S-b-d-MMA) & $528 \pm 10 \AA$ & $520 \pm 10 \AA$ \\
P(d-S-b-MMA) & $389 \pm 10 \AA$ & $390 \pm 10 \AA$ \\
P(d-S-b-d-MMA) & $452 \pm 10 \AA$ & $430 \pm 10 \AA$ \\
\hline
\end{tabular}

shown the excess copolymer on the surface is large enough so that the upper layer is fully connected with only small areas of the underlying, completed multilayer being evident. At equilibrium, the percentage of complete and incomplete layers will be dictated by the initial film thickness in relation to the period of the lamellar stacking. The appearance of the surface is reminiscent of a phase separation process. We do not know at this stage if the observed phenomenon should be related to a nucleation and growth process, to a growth of aggregates by coalescence or to a combination of the two. Also, the formation and the growth of the islands could involve exchanges of material between the incomplete top layer and the underlying completed multilayer. To address this basic question, kinetic experiments are presently in progress. Real time observations on the development of the interference colors in these copolymer films are being performed at different annealing temperatures.

In this study, only kinetics of depressions has been considered. It is of course of great interest to know if the behavior of elevations is similar to the one of depressions. Preliminary 
data seems to suggest it is not the case ; experiments are planned in the very next future to conclude on this important point.

In summary, when deposited on a silicon-substrate, symmetric diblock copolymers form, at equilibrium, a multilayer structure and if the top layer is incomplete, the formation of islands is observed in this layer. It is very attractive to draw a parallel between this behavior and the growth of clusters and aggregates in other two-dimensional systems $[17,18]$. Although the origins of the growth mechanism should be different in block copolymers, the similarity in their behavior should be noticed. For example, it could be fruitful to compare the present work with studies on phospholipid monolayers at the air-water interface which have revealed the formation of dense domains on a liquid sub-phase [19]. Block copolymer films could actually be considered as a potential model system for these types of studies.

This work was performed at the IBM Almaden Research Center and supported by IBM France and the Ministère Français de l'Education Nationale. We thank Dr. H. Werlich from the IBM Almaden Research Center for use of his microscope. The digitization of the images was performed at the Institut d'Optique (Orsay-France) and the image processing at the Laboratoire d'Optique Atmosphérique (L.O.A.) at the University of Lille (France). G. Coulon and D. Ausserré want to thank the Institut Curie (Paris), the Université Paris 6 and the CNRS for providing them the means to pursue this study in France.

\section{References}

[1] Leibler L., Macromolecules 13 (1980) 1602.

[2] Helfand E., Macromolecules 8 (1975) 552.

[3] Helfand E., Wasserman Z. R., Developments in Block Copolymers 1 Ed. Goodman I. (Applied Science, Essex, England) 1982, p. 99.

[4] OhTA T., KaWASAKi K., Macromolecules 19 (1986) 2621.

[5] Green P. F., Russell T. P., Jerome R., Granville M., Macromolecules 21 (1988) 3266.

[6] Anastasiadis S. H., Russell T. P., Satija S. K., Majkrzak C. F., J. Chem. Phys., submitted.

[7] Coulon G., Russell T. P., Deline V. R., Green P. F., Macromolecules 22 (1989) 2581.

[8] Anastasiadis S. H., Russell T. P., Satija S. K., Majkrzak C. F., Phys. Rev. Lett. 62 (1989) 1852.

[9] Processing, Structure and Properties of Block Copolymers, Ed. M. J. Folkes (Elsevier, New York) 1985.

[10] Developments in Block Copolymers Ed. Goodman I. (Applied Science, Essex, England) 1 (1982).

[11] Thomas H. R., O'Malley J. J., Macromolecules 12 (1979) 323.

[12] Green P. F., Christensen T. M., Russell T. P., Jerome R., Macromolecules 22 (1989) 2189.

[13] Hasegawa H., Hashimoto T., Macromolecules 18 (1985) 589.

[14] Henkee C. S., Thomas E. L., Fetters L. J., J. Mat. Sci. 23 (1988) 1685.

[15] Wittman J. C., Lotz B., Candau F., Kovacs A. J., J. Polym. Sci. Phys. Ed. 20 (1982) 1341.

[16] Françon M., Progress in Microscopy (Pergamon Press, Oxford) 1961.

[17] Thin Film Growth Techniques For Low Dimensional Structures, Ed. R. F. C. FARrow, S. S. P. Parkin, P. J. Dobson, J. H. Neave, A. S. Arrott, Nato A.S.I. Ser. B : Phys. 163 (Plenum Press, New York) 1987.

[18] Knobler C. M., Beysens D., Europhys. Lett. 6 (1988) 707.

[19] Ordering in Two-Dimensions, Ed. S. K. Sinha (North Holland, New York) 1980. 